\title{
Evaluation of Surfactant Performance in Fracturing Fluids for Enhanced Well Productivity in the Unconventional Reservoirs Using Rock-on-a-Chip Approach
}

\author{
Kai $\mathrm{He}^{1, *}$, Liang $\mathrm{Xu}^{1, *}$, Yuefeng $\mathrm{Gao}^{2}$, Xiaolong $\mathrm{Yin}^{2}$ and Keith Neeves ${ }^{3}$ \\ (1) Multi-Chem, a Halliburton Service, Houston, TX 77032, USA \\ (2) Petroleum Engineering, Colorado School of Mines, Golden, CO 80401, USA \\ (3) Chemical and Biological Engineering, Colorado School of Mines, Golden, CO 80401, USA \\ *: email: Kai.He@ halliburton.com and Liang.Xu@halliburton.com
}

\begin{abstract}
Proper application of surfactants during hydraulic fracturing operations not only enhances initial production of a reservoir, but also helps sustain its long-term production. The most commonly used surfactant for low-permeability reservoirs is a non-emulsifying surfactant (NES). This study shows that a weakly emulsifying surfactant (WES) is better in solubilizing oil globules via self-association, and appears to be more efficient at mobilizing oil through tight pore throats than NES. The fundamental difference between these two surfactant types was found to be the emulsion tendency. The performance of the two surfactants was compared using a microfluidic based Rock-on-aChip (ROC) device with pore sizes comparable to shale formation rocks. The ROC allowed direct visualization of oil recovery by surfactants with controlled pore geometries and surface chemistry. Results showed that the WES yielded higher oil recovery efficiency at equal driving pressure compared to a non-surfactant-bearing control fluid and the NES. As a result of the laboratory testing indications, a multiple well trial program was conducted in two separate areas of the Eagle Ford shale. Early production results suggest that wells treated with the WES exhibited enhanced productivity compared to those treated with the NES.
\end{abstract}

Keywords: Surfactant, Fracturing Fluids, Rock-on-a-Chip, Emulsion tendency, Eagle Ford shale, Well Productivity

(C) 2015. This manuscript version is made available under the Elsevier user license

http://www.elsevier.com/open-access/userlicense/1.0/ 


\section{Introduction}

A surfactant additive is an important component in fracturing fluids for ensuring a higher productivity from unconventional oil and gas formations. It has been previously demonstrated that wells treated with appropriate surfactant provide more effective fluid loss control and fluid flowback efficiency (Burman and Hall, 1986). Field production results from major liquids-rich shale plays in North America such as the Barnett, Eagle Ford, Bakken, and Permian Basin shale also suggest that there is a significant difference if correct application of a surfactant is executed (Paterniti, 2009; $\mathrm{Xu}$ and $\mathrm{Fu}, 2012$; $\mathrm{Xu}, 2013$ ).

Surfactant injection increases oil recovery primarily by reducing the interfacial tension between the aqueous and the oil phases. In addition, extended exposure of oil-wet rock surfaces to surfactant solution may alter the wettability of the surface, which has been shown to be effective to remove oil/water block in hydraulic fracture and in near wellbore matrix (Bang et al 2008; Yuan et al., 2011 and Yuan, 2012), although some studies show that field-scale wettability modification might not be economically useful due to the limitations imposed by molecular diffusion (Stoll et al., 2007). More importantly, when emulsions are stabilized by surfactant, emulsified oil droplets could effectively squeeze through tiny fractures (Cobos et al., 2009), and additional benefit may be achieved through improving the mobility ratio and the sweep efficiency due to the increased viscosity. However, in unconventional formations, the porosity and permeability tend to be extremely low (Rickman et al., 2010). It is thought that oil and water emulsions generated during the production could plug those tiny pores and severely impair production. Consequently, emulsions should be avoided. Notably, most commercially available non-emulsifying surfactants consist primarily of a small fraction of non-ionic surfactants and a rather large fraction of de-emulsifiers for fracturing application. The purpose of this formulation is to suppress the formation of oil and water emulsions during multiphase flow. This laboratory testing in conjunction with the field production data, however, prove otherwise that a weakly emulsifying surfactant can temporarily solubilize and mobilize oil globules, and thereby aid in additional oil production.

Recent developments in nanofabrication and optical microscopy provide methods for direct visualization of oil recovery in model porous media. This approach is called rock-on-a-chip (ROC). Through photolithography and etching techniques, the pore space of rock geometries with well-controlled porosity and permeability can be transferred into polymer, glass or silicon chips (Wu et al., 2012 and 2013; He et al., 2013 and 2014; Xu et al., 2014; Jacob et al., 2015). Real reservoir rock structures derived from tomography or microscopic images can be transferred into chips (Gunda et al., 2011). Notably, the pore throat size in these devices can be defined down to tens of nanometers, which matches those found in unconventional formations. Hence, this ROC approach potentially can be used to visually evaluate the performance of the surfactants for enhanced oil recovery in unconventional reservoirs in the laboratory.

In this study, we measure the emulsion behavior and the oil and aqueous phase separation rates between NES and WES and visualize their oil recovery on a silicon-based nanofluidic chip with random porous networks. We demonstrate that WES provides a better oil displacement efficiency than NES. Results of a multiple-well trial program in the Eagle Ford shale support the laboratory observations and show that wells treated with the WES exhibited enhanced productivity compared to those treated with the NES. This work provides compelling evidence that the ROC approach can be used to screen surfactants for hydraulic fracturing applications and the results are field-relevant.

\section{Experimental Methods}

Materials. Crude oil obtained from the Eagle Ford formation had an API number of 41.8 (density $=0.816 \mathrm{~g} / \mathrm{ml}$ ) and viscosity of $7.5 \mathrm{cP}$ at ambient temperature. The oil composition analysis showed that it had a total acid number of 0.01 and a total base number of 1.97 , suggesting that it contained more alkaline compounds, which are typically positively charged. Two commercial surfactants were used during the experiments. One was a field standard NES that usually does not generate emulsion with oil; the other was a WES that usually generates short-lived oil-in-water emulsion. Both surfactants were prepared in $4 \% \mathrm{KCl}$ with a concentration of $2000 \mathrm{ppm}$ for the ROC experiments. WES and NES have a density of 1.019 and $1.015 \mathrm{~g} / \mathrm{ml}$, respectively.

Emulsion Tendency: Two sets of $1000 \mathrm{ppm}$ of aqueous NES and WES were mixed with equal volumes of the crude oil in glass tubes. Samples were then placed in the oven overnight at the reservoir temperature of $180^{\circ} \mathrm{F}$. Prior to the ET test, samples were shaken for 10 minutes using a mechanical shaker. In addition, an oil-water sample 
without surfactants was used as the control. As soon as the shaking stopped, all samples were immediately placed in a sample rack and the oil/water interfaces were visually inspected and pictures were taken over a time period of 60 minutes. To quantify the phase separation rates between oil and water, another two sets of the surfactant samples were shaken with the same protocol and immediately placed in a LumiSizer (LS 611, Lum GmbH, Berlin). LumiSizer is an emulsion dispersion analyzer that uses light scattering to monitor how fast the oil separates from water, in the presence of surfactants at ambient temperature. In this study, the instability index was calculated to evaluate the emulsion behavior using the protocol described in Detloff et al. 2013.

Emulsion phase behavior tests with live crude were also performed. The live oil phase behavior were conducted in a high pressure, windowed, agitated, invertible, variable-volume view cell rated to $180^{\circ} \mathrm{F}$ and $1000 \mathrm{psi}$ that is housed with a constant temperature air bath. $30 \mathrm{ml}$ of dead oil and $30 \mathrm{ml}$ of the surfactant solution (NES or WES) were added to the sample volume. Once the cell and its contents were at $180^{\circ} \mathrm{F}$, methane from a high pressure cylinder at $\sim 1500$ psi was allowed to flow directly into the top of the sample volume until the pressure of the sample volume was slightly above $1000 \mathrm{psi}$, filling the small gas space in the sample volume with high pressure methane. The three phases (aqueous, oil and gas) were then residing in the sample volume at $180^{\circ} \mathrm{F}$ and $\sim 1000 \mathrm{psi}$. The sample volume was then vigorously mixed for 2 minutes with a magnetically driven slotted fin impeller at the top of the sample volume spinning at about $2500 \mathrm{rpm}$. All three phases were intimately mixed and the entire sample volume was opaque during mixing. A slight drop in pressure occurred as more methane dissolved into the oil during mixing, but the pressure then stabilized and remained at a value close to $1000 \mathrm{psi}$. The emulsion behaviors were then imaged when the mixing ceased.

Nanofluidic Chip Fabrication. The nanofluidic chip was fabricated using methods described by Mao and Han (2011). Fig. 1 illustrates a schematic of the nanofluidics chip. The pore structures were defined in double-sided polished $\langle 100\rangle$ silicon wafers (thickness $=250 \mu \mathrm{m})$ with low-stress silicon nitride $(\sim 100 \mathrm{~nm})$ on both sides. First, a random porous network consisting of nanochannels with an area of $400 \times 600 \mu \mathrm{m}^{2}$ and channel width of $3 \mu \mathrm{m}$ was defined using a deep reactive ion etching based on a Voronoi tessellation method developed by Wu et al. (2012). The nanochannel depth was approximately $300 \mathrm{~nm}$, which is defined as the pore throat size, and the estimated porosity was $20 \%$. Next, two microchannels with widths of $10 \mu \mathrm{m}$ were defined on both sides of the random porous network. Finally, a back side deep reactive ion etching through the wafer was performed to generate the inlet and outlet holes at the four ends of the microchannels. The fabricated device was then anodically bonded to a thin Pyrex coverslip (Pyrex 7740, $40 \times 20 \times 0.25 \mathrm{~mm}$ ). Following anodic bonding, the device was exposed to tridecafluoro1,1,2,2-tetrahydro-octyl-trichlorosilane (Gelest, Inc.) vapor overnight under vacuum at room temperature. Such treatment results in a uniform oil-wet surface condition. To prevent contamination of the surface, the entire device was rinsed with deionized (DI) water and methanol, and then dried using nitrogen gas before use.

Experimental Procedure and Setup. Fig. 2 shows the schematic of the experimental setup, which is similar to that presented in Wu et al. (2013). A nitrogen source was connected to two capillary tubes through pressure regulators. The capillary tubes served as reservoirs of fluids (oil, $4 \% \mathrm{KCl}$ solution, $2000 \mathrm{ppm}$ surfactant solution), and were connected to the nanofluidic device through PEEK $^{\mathrm{TM}}$ tubing (inside diameter (ID)/outside diameter (OD): 150/360 $\mu \mathrm{m})$. The experiments were performed at the ambient temperature.

The procedures to perform the nanofluidic experiments are as follows:

1. The crude oil was pre-filtered using a $0.22 \mu \mathrm{m}$ nylon filter, and then injected at a pressure of $10 \mathrm{psi}$ to fill both the microchannels and the nanochannels between the microchannels. The channel surface has a wettability that prefers the oil to the air. As a result, this process did not leave any air trapped inside the nanofluidic device.

2. A constant flow of the crude oil through one of the two microchannels was established by maintaining a pressure difference of $10 \mathrm{psi}$ between the inlet and the outlet of the microchannel (oil microchannel). The inlet pressure was regulated using a precision pressure regulator (MediaGauge ${ }^{\mathrm{TM}}$ digital pressure gauge, $0.01 \mathrm{psi}$ ) connected to a nitrogen gas cylinder, monitored by a digital pressure gauge (Victor Edge Series Regulator, $5 \mathrm{psi}$ ). The outlet was open to the atmosphere. This flow established a pressure of $5 \mathrm{psi}$ at the nanochannel-oil microchannel junction because the junction was located half-way between the inlet and outlet of the oil microchannel.

3. The $\mathrm{KCl}$, or surfactant solution, was then injected into the other microchannel (water microchannel), at a pressure of $10 \mathrm{psi}$. The outlet of the water microchannel was also open to the atmosphere. After a constant flow of the surfactant solution was established, the pressure at the nanochannel water microchannel junction was also 5 psi because the junction was half-way between the inlet and outlet of the oil microchannel. Because the hydrodynamic resistance in the nanochannels was much higher than 
Imaging Processing. To visualize the oil recovery and compare the oil displacement efficiency, image processing was conducted using the method of image subtraction. First, when one microchannel is filled with water and another microchannel and the nanochannels are filled with oil, a gray-scale tiff image of the chip was taken (gray-scale value is between 0 to 255 , with 0 being pure black and 255 being pure white). This image was loaded into MATLAB as the background. When the pressure in the water microchannel exceeded the capillary entry pressure, water would enter the nanochannel network, displace the oil, and reach the other microchannel. After breakthrough, a steady-state water saturation was established. At this time, another gray-scale tiff image was taken. Then, the initial background was subtracted from the new tiff image. Since water and oil have different gray-scale values under the imaging condition, water saturation is thus highlighted in the subtracted image.

The method to determine the water saturation is as follow. First, we identify a region in the subtracted image that does not contain any fluids. In this region, the mean of the gray-scale values of the pixels is nearly zero and the standard deviation $\sigma$ reflects the noise of imaging. Oil is considered to be replaced by water, when the gray-scale of the pixel in the subtracted image is higher than $3 \sigma$, which corresponds to a confidence interval of $99.7 \%$.

Oil Recovery. The performance of NES and WES was also compared based on the oil recovery using crushed core measurement. It is challenging to apply extremely high differential pressures across low-permeability core plugs to perform a core flood test. In addition, the oil recovery from the core plugs is typically so low that the results are not reproducible and cannot be used to compare the surfactant performance. In this respect, we took a different approach: the low-permeability core plug was crushed to small sizes (100-mesh) and then re-saturated with crude oil or condensate from the reservoirs at reservoir temperatures for an extended period of time. The re-saturated core particles were then packed into a high-pressure column (Western Analytical Products, Inc) and the frac water containing the surfactant was passed through the column at the flow rate of $3 \mathrm{ml} / \mathrm{hr}$. The effluent is then collected and the oil recovery by different surfactants can be quantified and compared using an InfraCal analyzer (InfraCal 2 ATR-SP, Wilks). The method of using crushed cores (GRI method) to study the permeability, porosity and fluid saturations in unconventional shale reservoirs has been extensively reported in literature (Handwerger et al., 2011; Wilson et al., 2012; Profice et al., 2012 and Shafer et al., 2013;). Several advantages of using crushed-shale pack were identified such as confined volume, isotropic nature and good pore connectivity (Xu and Dehghanpour, 2014).

\section{Results and Discussion}

Comparison of NES and WES. The emulsion phase behavior of oil/surfactant/brine water is closely related to the ultimate oil recovery (Hirasaki et al, 2004). Two surfactants NES and WES were chosen to demonstrate their fundamental differences. They are similarly efficient at lowering the IFT between the aqueous phase and the crude as shown in Table 1.

As their nomenclatures imply, the non-emulsifying surfactants (NES) do not typically generate emulsions upon contact with crude oil or condensate. By using NES, it is thought that any potential emulsion blocks in the formations can be eliminated or avoided, thereby opening up the flow area for the oil and gas. This idea, however, appears to neglect the classical oil extraction mechanisms that are necessary to mobilize the oil, where oil droplets must be able to squeeze through the tiny pore throats so as to reach the propped fractures (Cobos et al., 2009). It is well known that the formation of a weak emulsion between oil and water that is temporarily stabilized by surfactants is necessary to mobilize the oil droplets, as witnessed in many alkaline-surfactant-polymer (ASP) floods in conventional sandstone and carbonate reservoirs (Hirasaki et al., 2004). A recent study by Rane et al., also showed that WES can reduce the elasticity and rigidity of oil-water interface making the interface more deformable and squeezable for the flow of oil droplets through porous media. Such mechanism can help to increase oil recovery in the reservoir by mobilizing additional oil globules (Rane et al., 2015). In theory, the oil-water emulsion tends to 
phase separate because of unfavorable interactions (Shramm, 2010). However, in the presence of weakly emulsifying surfactants (WES), it is then possible to alter the interactions of oil and water at the interface, thus a weak emulsion can be temporarily created and last for a short period of time, depending on the surfactant concentrations, among other factors. The primary rationale for the presence of a temporary weak emulsion is its strong capability to solubilize and mobilize oil globules. As illustrated in Fig. 3, the surfactant molecules tend to diffuse to the interface between an isolated oil droplet and water in the surrounding environment, because of surface tension gradient or the Gibbs-Marongoni effect (step 1) (Shramm, 2010). As soon as the surfactants start to displace the oil molecules that are attached to the surface, the isolated oil droplet will tend to roll up slowly and eventually detach from the surface (step 2) (Kao et al, 1988). When there is plenty of surfactants around, the extra surfactant molecules start to self-associate and form spherical aggregates or micelles with oily cores (step 3), which come together and form oil-in-water emulsions. When this occurs, much more oil can be solubilized inside surfactant aggregates or micelles (Kao et al., 1988, Salager et al., 2005) and they can be produced to the nearby propped fractures. More importantly, oil droplets with surfactants at the interface can now readily deform and possibly squeeze through pore throats in the formation or propped fractures because of the low interfacial tension. This process is illustrated in Fig. 4. Conversely, because the chemistry and the activity of surfactant solutions can be controlled for various oil and gas formations, emulsification is short-lived in nature and the emulsions break and reform continually during flow. Hence, tight emulsions can be avoided and no emulsion blocks are generated in the formation or fractures.

To demonstrate the presence of a temporary weak emulsion, the emulsion phase behavior and the phase separation rates of NES and WES are shown in Fig. 5 and Fig. 6, respectively. As soon as the shaking stopped, both the emulsion phases started to shrink. However, WES always had a larger portion of emulsion phase than NES over time. More importantly, the weak emulsion in WES completely broke after 10 minutes, an indication of the temporary nature of the emulsion and no generation of tight emulsion blocks. Such phase behavior was precisely captured in the light scattering measurements using LumiSizer, where the instability index (defined by the clarification at a given separation time, divided by the maximum clarification) represents the portion of the samples that has separated (e.g. if the index is 1, it corresponds to a single oil phase and a single water phase and $100 \%$ of the samples have separated). Thus, it is evident from Figure 6, that WES has a slower phase separation rate than NES, which is consistent with its weakly emulsifying characteristics. Fig. 7 provides additional insights by examining the emulsion fingerprints within 1200s, where WES and NES consist of the oil phase, emulsion phase and water phase, respectively. Clearly, WES had a wider emulsion phase than NES. Because WES had a slower phase separation rate, it is more capable of solubilizing oil molecules inside its micelles.

We further investigate the emulsion phase behavior impacted by live oil. Fig. 8 show the emulsion phase behavior as a function of time at live oil condition $\left(\mathbf{1 8 0}^{\circ} \mathrm{F}, 1000 \mathrm{psi}\right.$, oil saturated with methane at $\left.1000 \mathrm{psi}\right)$. The results indicate that the inherent characteristic of NES and WES was not influenced by the live oil. WES is still more capable of temporarily emulsifying oil globules.

\section{Pore-scale visualization in ROC}

Non-Surfactant-Bearing Fluid Flooding. The non-surfactant-bearing fluid $4 \% \mathrm{KCl}$ solution was injected into the nanofluidic chip to displace the crude oil. Fig. 9 presents the processed images that highlight the replacement of crude oil by the control fluid at various pressure differences 14, 15, 17.5, and 20 psi across the random porous network. It was observed that brine breakthrough occurred at 14 psi. Breakthrough was defined as the time when the control fluid reached the oil channel. Importantly, it was observed that oil saturation did not decrease after breakthrough when the pressure was held constant. It is likely that most of the displacing fluid simply followed the path of the least resistance and left the majority of oil behind. Fig. 9 a-d also indicate that oil saturation decreases with increasing pressure, suggesting sufficient pressure drop or drawdown could eventually overcome capillary forces and drive more oil out of this random porous network with a pore throat size of $300 \mathrm{~nm}$.

WES Flooding. A WES prepared in $4 \% \mathrm{KCl}$ was injected into the nanofluidic chip for the crude oil displacement. Fig. 10 illustrates the processed images of oil displacement at pressure differences of 5, 10, and 15 psi across the random porous network. Compared to the raw image of displacement by the control fluid (Figure 11a), it was observed that the contrast between the crude oil and surfactant solution was very low in the raw image of WES flooding (Figure 11b), and the breakthrough pattern was barely detected; this was probably caused by the emulsified oil droplets or thin oil film attached onto the surface of the random porous network (Fig. 11c) that lowered the contrast. However, the increase in the oil saturation with increasing pressure difference was still 
observed after image subtraction (Fig. 10a through c). Notably, the displacement pattern was more uniform when the oil was displaced using the WES rather than the control fluid, which indicated that the surfactant significantly lowered the capillary pressure and modified the front movement of the flooding fluid into more piston-like. Additionally, it is clear that, at $15 \mathrm{psi}$, more crude oil was recovered using the WES than the control fluid.

Using imaging method described earlier, we calculated the saturations of the aqueous phase at different pressure drops across the nanochannel network for $4 \% \mathrm{KCl}$ flooding and WES flooding. These data are shown in Fig. 12.

NES flooding. A NES prepared in 4\% $\mathrm{KCl}$ was injected into the nanofluidic chip to displace the crude oil. Fig. 13a and $\mathbf{b}$ illustrate the processed images of oil displacement at pressure differences of 5 and 10 psi. It appears that an early breakthrough probably occurred at $10 \mathrm{psi}$; however, the oil saturation change between 5 and 10 psi was barely noticeable because of the poor contrast.

The results of three tests on the nanofluidic chip indicate that surfactants could significantly lower the capillary pressure, thus modifying the displacement front such that it is more piston-like. At the same driving pressure, compared to a non-surfactant-bearing control fluid, WES yielded higher oil recovery. The piston-like displacement pattern of the WES flooding could translate to higher oil recovery efficiency. It is also hypothesized that the WES could be more efficient in surface cleanup because of potential ion-pair interactions between the WES and oil (Salehi, M. et al., 2008; Feng and Xu, 2015). An even lower contrast was observed between the oil and displacing fluid in NES flooding, probably due to the residual oil droplets in the primary channels of the network or thin oil films on the network surface. As a result, the oil recovery was impossible to determine accurately. Additionally, an early breakthrough at approximately 10 psi for the NES flooding probably suggested that the NES did not appear to have any appreciable interaction with oil molecules in the network. Similar to the control fluid, the NES fluid could have simply bypassed most of the oil and developed breakthrough prematurely. However, more data are needed to prove these hypotheses and this warrants further study. Notably, in order to further confirm the performance of WES and NES, we performed the oil recovery tests on the crushed, re-saturated shale cores, the results indicate that WES recovered more oil than NES as shown in Fig. 14.

\section{Production Comparison}

Production data of a WES and a field standard NES in 45 wells separated in two areas in the Eagle Ford shale was compared to validate the laboratory results. Those wells had minor difference in formation geometry and chemistry. The strategies of the fracturing process were also similar. Detail information regarding those wells is provided in the supporting information (Table S1 and S2). Figs. 15 and 16 illustrate the production data for these wells up to 30 and 90 days, respectively. For comparison, those data were normalized by lateral lengths and fracturing stages (normalized cumulative oil or gas production= cumulative oil or gas production divided by number of fracturing stages, then divided by total lateral length), which isolates the effect of production well size and surfactant usage. To compare the field performance, an average of the production data was calculated. As Figs. 17 and 18 illustrate, the WES had a better performance than the NES in terms of both the 30- and 90-day production data for two different areas, respectively.

\section{Conclusions}

NES and WES were quantified and differentiated in terms of emulsion tendency. Contrary to conventional wisdom, WES was capable of temporarily solubilizing and mobilizing the oil globules in its aggregates or micelles and thus enabling additional oil production, without causing the emulsion blocks. This theory is supported by data generated in a microfluidic based ROC device with controlled surface chemistry and pore geometry. Results indicate that the WES was more effective in enhancing oil recovery in the unconventional formations. Oil and gas production data from the Eagle ford further validated the laboratory results and indicate that wells treated with WES exhibited enhanced productivity compared to those treated with NES.

\section{Acknowledgements}

$\mathrm{KH}$ and LX thank the Multi-Chem management team and Halliburton for their permission to publish this paper. KBN and XY thank the Research Partnership to Secure Energy for America (09122-29) and the Unconventional Natural Gas and Oil Institute, Coupled Integrated Multiscale Measurements and Modeling Consortium for support. A portion of this research was conducted at the Center for Nanophase Materials Science, which is sponsored at Oak Ridge National Laboratory by the Scientific User Facilities Division, Office of Basic Energy Science, US Department of Energy. 


\section{References}

Burman, J.W. and Hall, B.E. 1986. Foam as a Diverting Technique for Matrix Sandstone Stimulation. Paper SPE 15575 presented at the SPE Annual Technical Conference and Exhibition, New Orleans, Louisiana, USA, 5-8 October. http://dx.doi.org/10.2118/15575-MS.

Paterniti, M. L. 2009. Microemulsion Surfactant Increases Production in the Codell Formation of the DJ Basin. Presented at the SPE Rocky Mountain Petroleum Technology Conference, Denver, Colorado,USA, 14-16 April. SPE-116237-MS. http://dx.doi.org/10.2118/116237-MS.

$\mathrm{Xu}, \mathrm{L}$. and Fu, Q. 2012. Ensuring Better Well Stimulation in Unconventional Oil and Gas Formations by Optimizing Surfactant Additives. Presented at the SPE Western Regional Meeting in Bakersfield, California, USA, 19-23 March. SPE 154242-MS. http://dx.doi.org/10.2118/154242-MS.

$\mathrm{Xu}$, L. 2013. Optimizing Surfactant Additives for Low-Permeability Wet Gas Formations: A Laboratory Approach for Correlating Capillary Pressure and Emulsion Tendency with Surfactant Performance. Presented at the SPE Eastern Regional Meeting, 20-22 August, Pittsburgh, Pennsylvania, USA, 20-22 August. SPE 165697-MS. http://dx.doi.org/10.2118/165697-MS.

Bang, V., Yuan C., Pope, G.A., Sharma, M.M.: Improving Productivity of Hydraulically Fractured Gas Condensate Wells by Chemical Treatment. OTC19599, presented at the SPE Offshore Technology Conference held in Houston, Texas, U.S. A.,5-8 May 2008

Yuan, C : The Chemical Treatment to Remove Liquid Block in Hydraulic Fractured Well-A Simulation Study with Leak-Off, SPE 158190-PP, the 2012 Energy Conference-Developing Resources for Sustainability, June 11 13, 2012, Port-of-Spain, Trinidad.

Yuan, C., Pope, G.A, and Sharma, M.M: The Modeling of Solvents Flow-Back in the Chemical Treatment to Remove Liquid Block, IPTC-15219-PP, presented in the International Petroleum Technology Conference (IPTC), 7-9 February 2011, Bangkok, Thailand.

Stoll, Martin, et al. "Toward field-scale wettability modification-the limitations of diffusive transport." SPE Reservoir Evaluation \& Engineering 11.03 (2008): 633-640.

Cobos, S., Carvalho, M.S., and Alvarado, V., Flow of Oil-Water Emulsions Through a Constricted Capillary, International Journal of Multiphase Flow, Vol. 35, pp. 507-515, 2009

Rickman, R.D. and Jaripatke, O. 2010. Micro-Emulsion/Surfactant Packages for Shale and Tight Gas Reservoirs. Paper SPE 131107 presented at the Deep Gas Conference and Exhibition, Manama, Bahrain, 24-26 January. doi: 10.2118/131107-MS.

Wu, M. Xiao, F., Johnson-Paben, R.M. Retterer, S.T., Yin, X., and Neeves, K.B. 2012. Single-and Two-phase Flow in Microfluidics Porous Media Analogs based on Voronoi Tessellation. Lab on a Chip. 12 (2). $253-261$. http://dx.doi.org/10.1039/c1lc20838a.

Wu, Q., Ok, J.T., Sun, Y., Retterer, S.T, Neeves, K.B, Yin, X., Bai, B., and Ma, Y. 2013. Optic imaging of single and two-phase pressure-driven flows in nano-scale channels. Lab on a Chip. 13: 1165-1171. http://dx.doi.org/10.1039/C2LC41259D.

$\mathrm{Xu}$, W., Ok, J.T., Xiao, F. et al. 2014. Effect of pore geometry and interfacial tension on water-oil displacement efficiency in oil-wet microfluidic porous media analogs. Physics of Fluids (1994-present) 26 (9): 093102.

He, K. Khorasani, F.B., Retterer, S.T, Thomas, D.K., Conrad, J.C., and Krishnamoorti, R. 2013. Diffusive Dynamics of Nanoparticles in Arrays of Nanoposts. ACS Nano. 7 (6): 5122-5130. http://dx.doi.org/10.1021/nn4007303.

He, K., Retterer, S. T., Srijanto, B. R., Conrad, J. C., \& Krishnamoorti, R. (2014). Transport and Dispersion of Nanoparticles in Periodic Nanopost Arrays. ACS nano.

Jacob, J. D. C., He, K., Retterer, S. T., Krishnamoorti, R., \& Conrad, J. C. (2015). Diffusive dynamics of nanoparticles in ultra-confined media. Soft matter.

Gunda, N.S., Bera, B., Karadimitriou, N.K., Mitra, S.K., and Hassanizadeh, S.M. 2011. Reservoir-on-a-chip (ROC): a new paradigm in reservoir engineering. Lab on a Chip. 11 (22): 3785-3792. http://dx.doi.org/10.1039/c11c20556k.

T. Detloff, T. Sobisch, D. Lerche, Instability Index, Dispersion Letters Technical. T4 (2013) 1-4.

Mao, P. and Han, J. 2011. Fabrication and characterization of $20 \mathrm{~nm}$ planar nanofluidic channels by glass-glass and glass-silicon bonding. Lab on a Chip. 5 (8): 837-844.

Handwerger, D. A., Keller, J., \& Vaughn, K. (2011, January 1). Improved Petrophysical Core Measurements on Tight Shale Reservoirs Using Retort and Crushed Samples. Society of Petroleum Engineers. doi:10.2118/147456-MS

Wilson, A. (2012, August 1). Advances in Measuring Permeability Address Shortcomings of Crushed-Rock Technique. Society of Petroleum Engineers. doi:10.2118/0812-0057-JPT 
Profice, S., Lasseux, D., Jannot, Y., Jebara, N., \& Hamon, G. (2012, December 1). Permeability, Porosity and Klinkenberg Coefficien Determination on Crushed Porous Media. Society of Petrophysicists and Well-Log Analysts.

Shafer, J. (2013, December 1). Recent Advances in Core Analysis. Society of Petrophysicists and Well-Log Analysts.

Xu, M., \& Dehghanpour, H. (2014). Advances in understanding wettability of gas shales. Energy \& Fuels, 28(7), $4362-4375$.

Hirasaki, G., Zhang, D.L. 2004. Surface Chemistry of Oil Recovery From Fractured, Oil-Wet, Carbonate Formations. SPE Journal, 9 (2): 15-162. doi: 10.2118/88365-PA.

Rane, Jayant P., and Liang Xu. "Proper Selection of Surfactants for Enhanced Oil Recovery Applications Based on Interfacial Rheology Measurements of Oil-Water Interfaces." SPE International Symposium on Oilfield Chemistry. Society of Petroleum Engineers, 2015.

Shramm, L.L.; Surfactants: Fundamentals and Applications in the Petroleum Industry, Cambridge University Press, Reissue edition (November 25, 2010)

Kao, R.L., Wasan, D.T., Nikolov, A.D., Edwards, D.A., Mechanisms of Oil Removal from a Solid Surface in the Presence of Anionic Micellar Solutions, Colloids and Surfaces, 34, pp. 389, 1988

Salager, J.L., Anton, R.E., Sabatini, D.A., Harwell, J.H., Acosta, E.J., Tolosa, L.I., Enhancing Solubilization in Microemulsions - State of the Art and Current Trends, Journal of Surfactants and Detergents, Vol. 8, Issue 1, pp. 3-21, 2005

Salehi, Mehdi, Stephen J. Johnson, and Jenn-Tai Liang."Mechanistic study of wettability alteration using surfactants with applications in naturally fractured reservoirs." Langmuir 24.24 (2008): 14099-14107.

Feng, L., \& Xu, L. (2015, January 26). Implications of Shale Oil Compositions on Surfactant Efficacy for Wettability Alteration. Society of Petroleum Engineers. doi:10.2118/172974-MS 

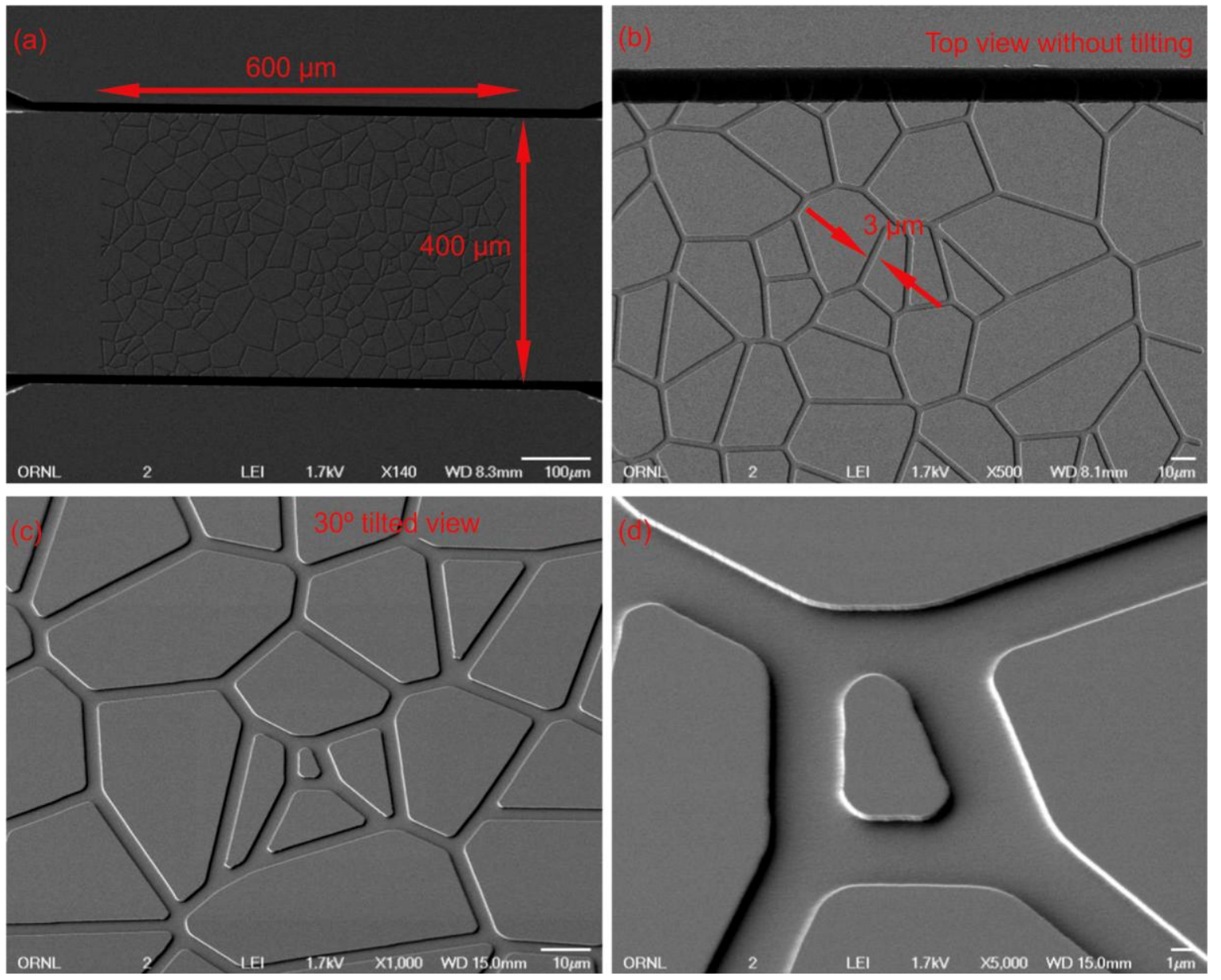

Fig. 1-Electron micrographs of nanofluidic chip with the random porous network area of $400 \times 600 \mu \mathrm{m}^{2}$. (a) An overview of the nanofluidic device. (b) A top view of the random porous network. (c) A $30^{\circ}$ titled view of the random porous network. (d) A high magnification view of the pore structure. 


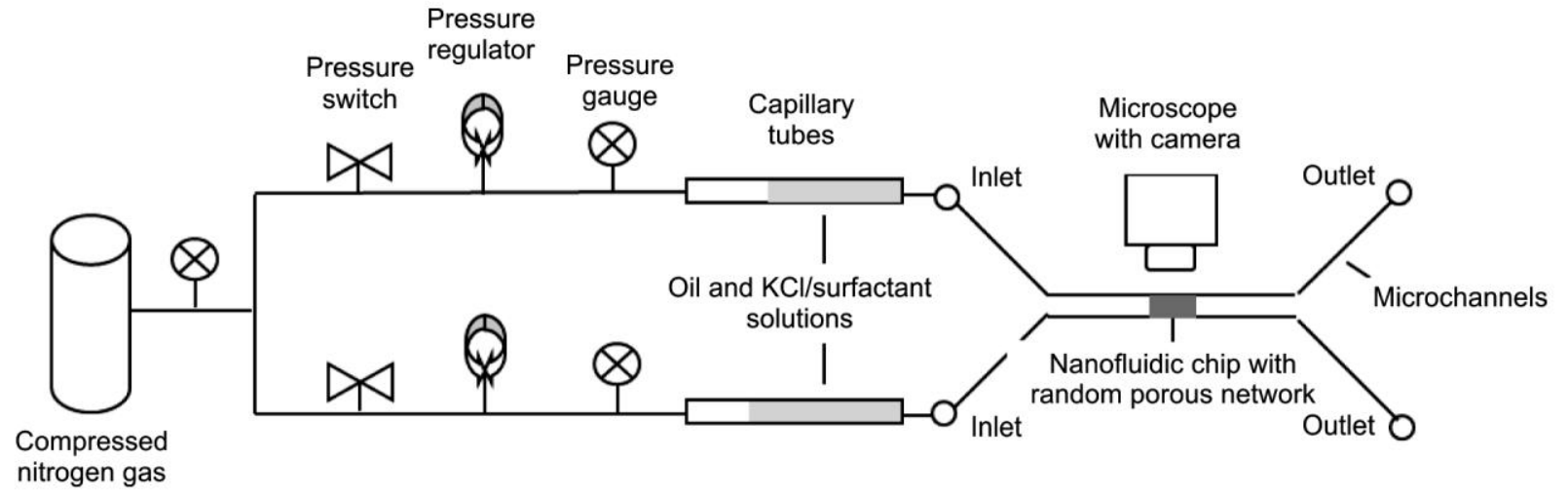

Fig. 2 - Schematic of experimental setup and nanofluidic chip.

\section{Surfactant in water}

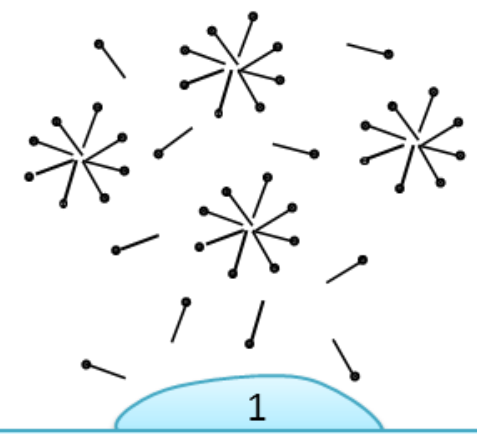

Oil solubilized in micelles

Fig.3 - Roll-up (step 1), detachment (step 2) and solubilization of oil droplets (step 3) in the presence of surfactant monomers and micelles.
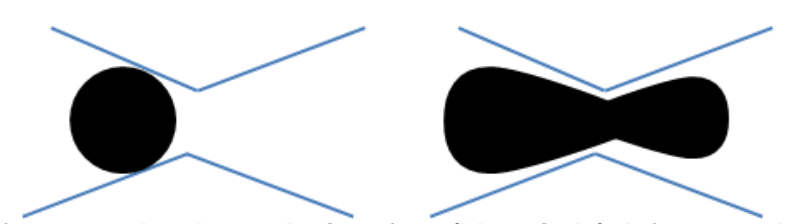

Fig. 4 - An oil droplet with surfactant molecules at the interface (blue circle) deforms and squeezes through a pore throat enabled by a low IFT. 


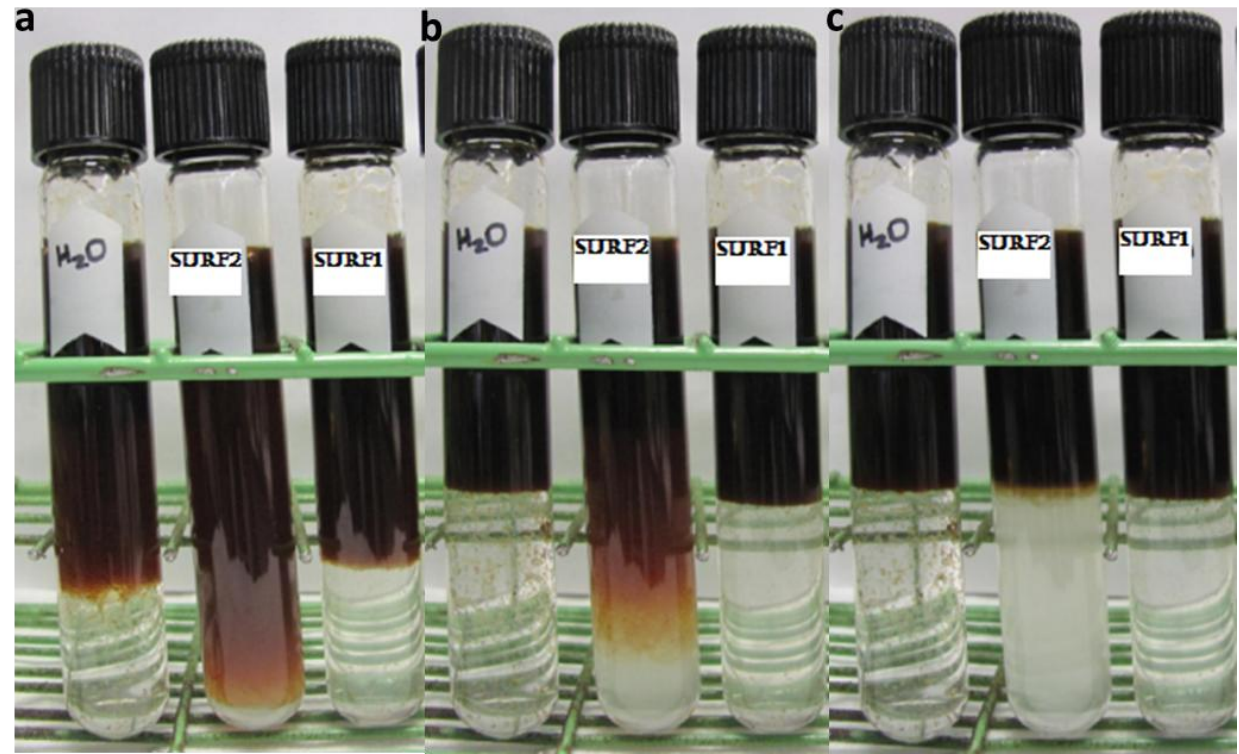

Fig.5-Emulsion phase behavior as a function of time at the reservoir temperature: a. $120 \mathrm{~s} ;$ b. $300 \mathrm{~s} ; \mathrm{c} .600 \mathrm{~s}$. SURF1 = NES, SURF2 $=$ WES.

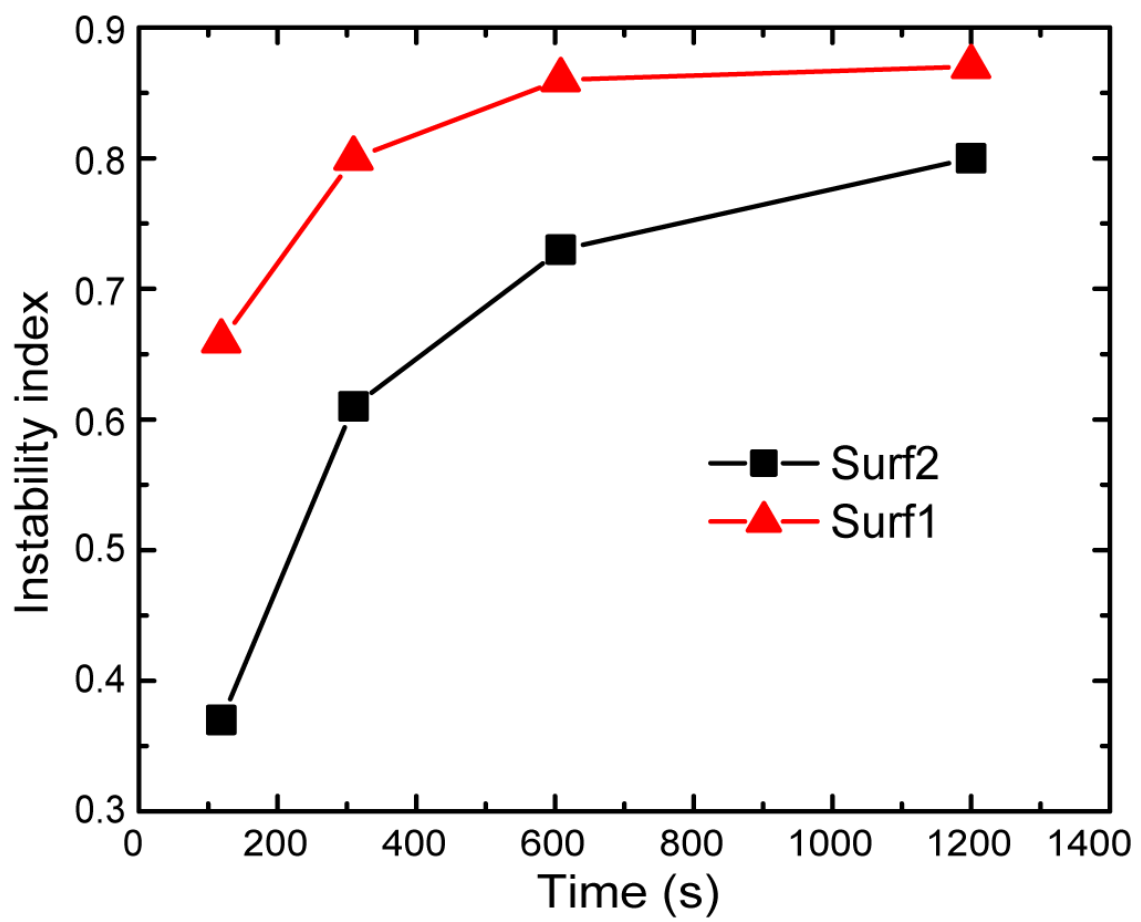

Fig.6-Instability or phase separation index vs. time 

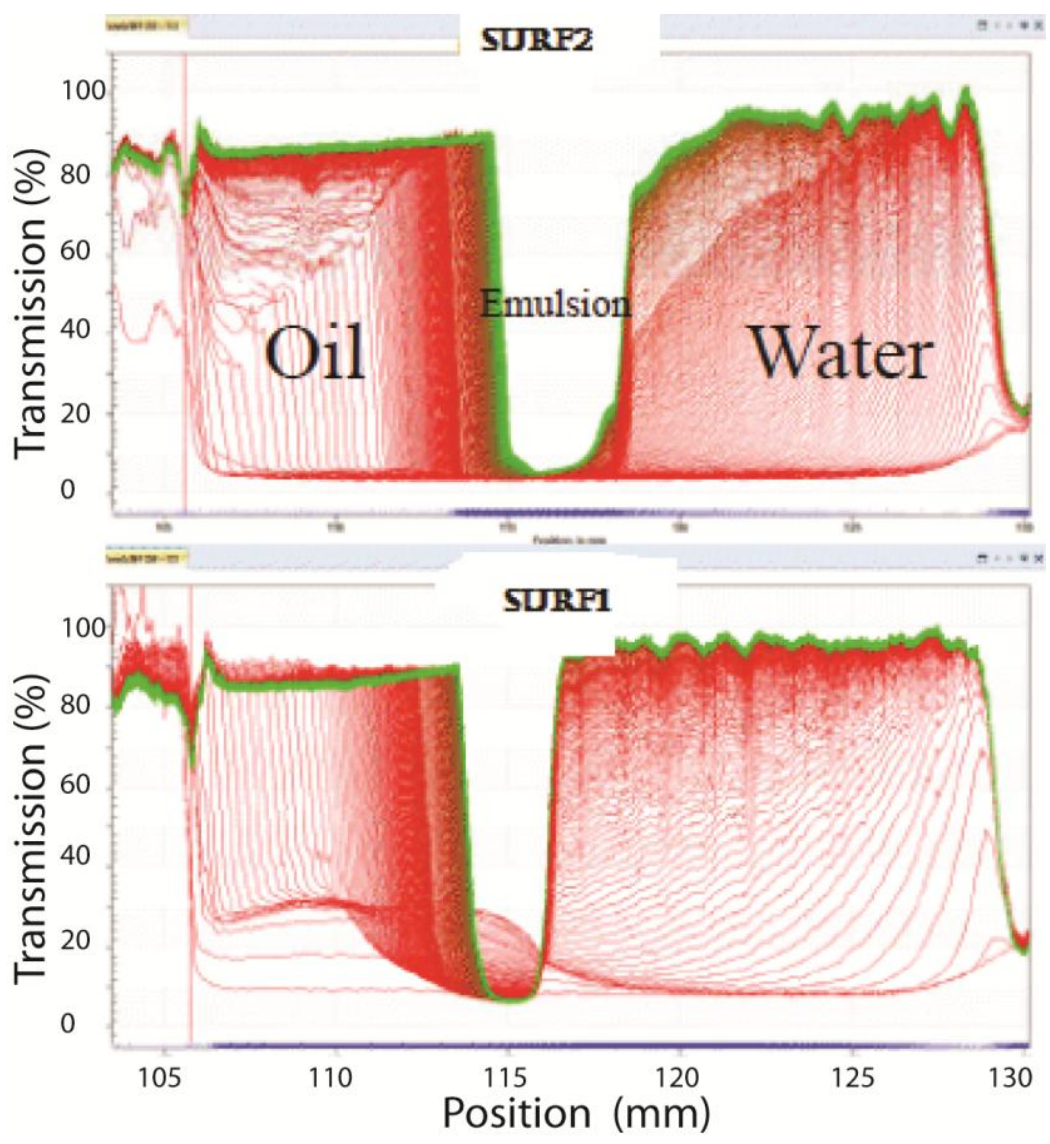

Fig.7 - Emulsion fingerprints within 1200 seconds. The emulsion phase consists of many tiny emulsion droplets and hence has low light transmission. Line color gradient signifies time progression, green is the last snapshot. 


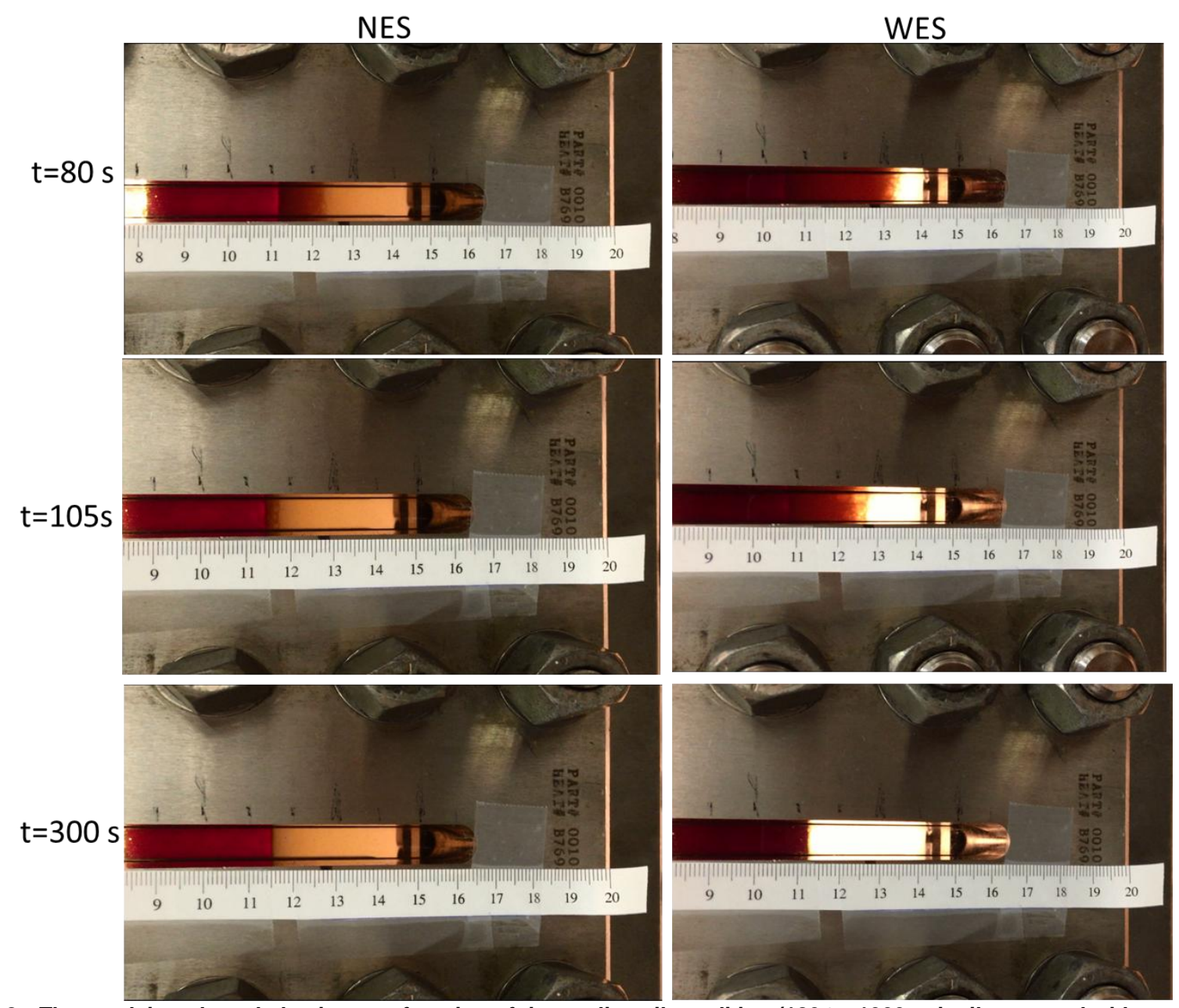

Fig. 8-The emulsion phase behavior as a function of time at live oil condition $\left(180^{\circ} \mathrm{F}, 1000 \mathrm{psi}\right.$, oil saturated with methane at $1000 \mathrm{psi})$. Note: the aqueous phase was not red to the eye in NES test, which is a lighting effect. 
Fig. 9-Processed optical micrographs of crude oil displacement by control fluid $4 \% \mathrm{KCl}$ at pressure differences of (a) 14 , (b) 15, (c) 17.5, and (d) 20 psi.

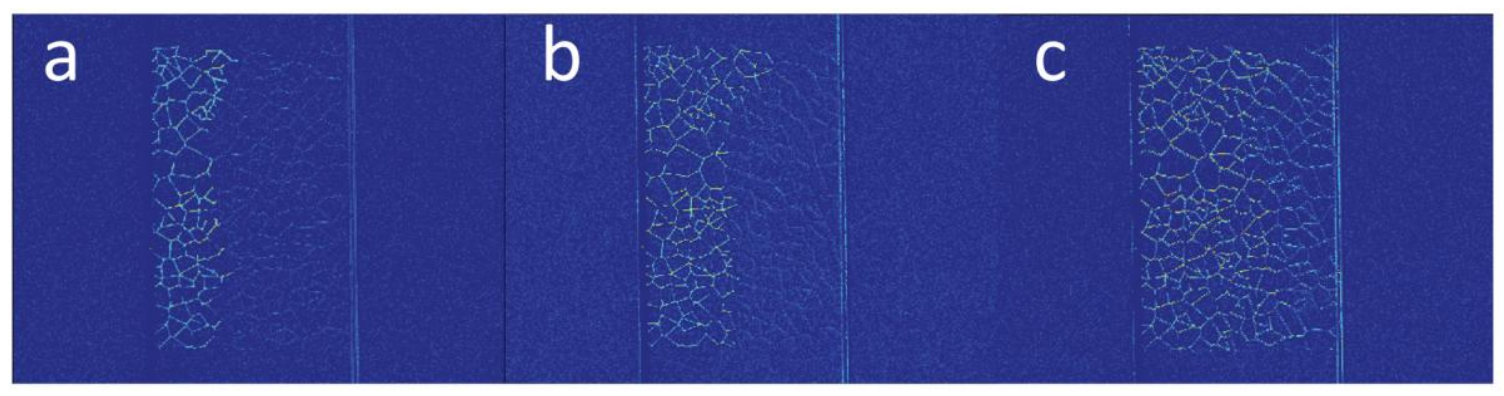

Fig. 10-Processed optical micrographs of crude oil displacement using WES at pressure differences of (a) 5, (b) 10, and (c) 15 psi. 
Fig. 11-Optical micrographs of crude oil displacement using the (a) control fluid at the pressure difference of 15 psi, (b) WES at the pressure difference of $10 \mathrm{psi}$, and (c) observed emulsified oil droplet. Control fluid flooding shows a good contrast, while WES flooding shows a very low contrast.

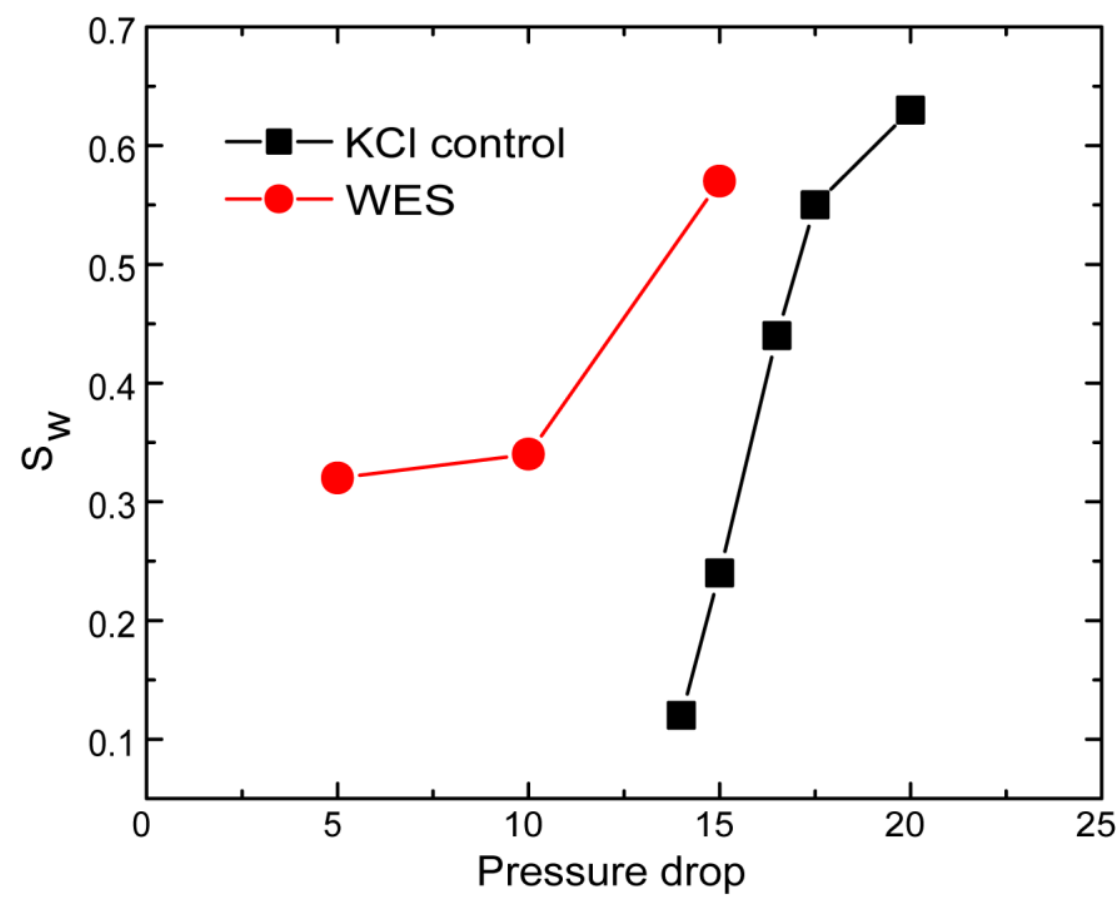

Fig. 12 - Water saturation in the nanochannel network as a function of pressure drop across the network.

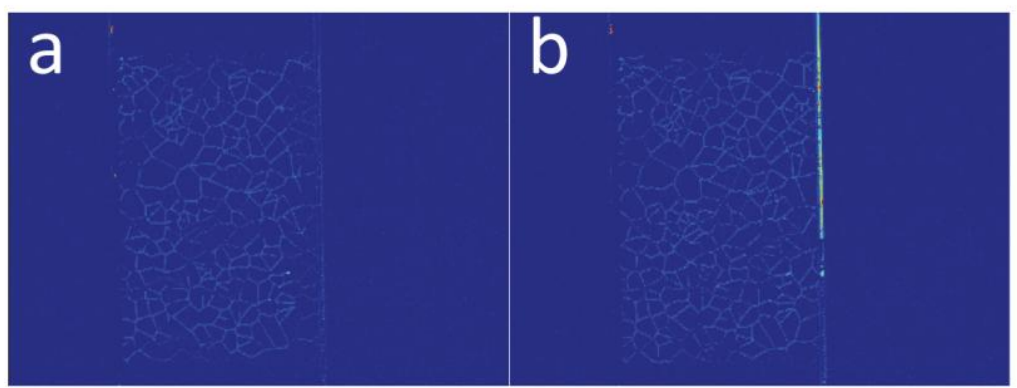

Fig. 13-Processed optical micrographs of crude oil displacement using NES at pressure differences of (a) 5 and (b) 10 psi. 
Fig. 15-30-day production data of 45 wells in two separate areas in the Eagle Ford shale. In Area 1, Wells 1 through 7 were treated with WES, and Wells 8 through 23 were treated with NES. In Area 2, Wells 24 through 31 were treated with WES, and Wells 32 through 45 were treated with NES.

Fig. 14-Oil recovery lab results suggest that Surf 2 (weakly emulsifying surfactant) extracted more oil than Surf 1 (nonemulsifying surfactants).
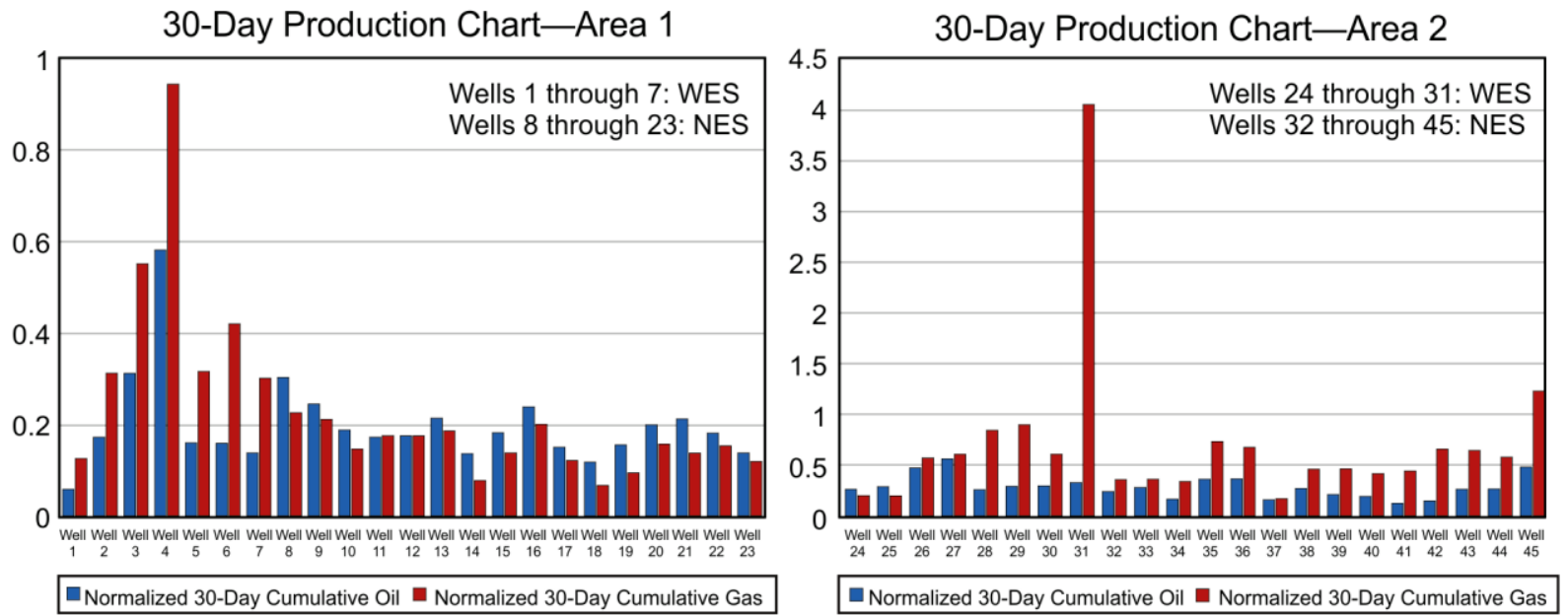
90-Day Production Chart-Area 2

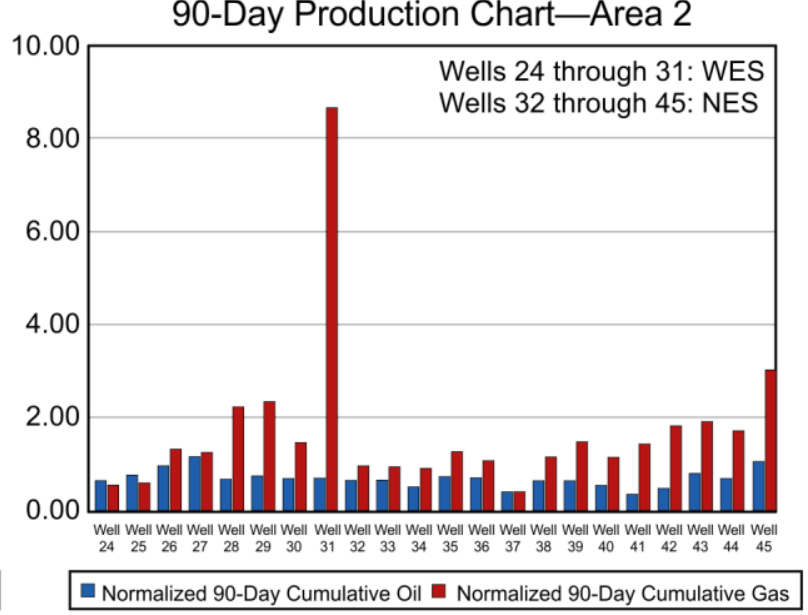

Fig. 16-90-day production data of 45 wells in two separate areas in the Eagle Ford shale. In Area 1, Wells 1 through 7 were treated with WES, and Wells 8 through 23 were treated with NES. In Area 2, Wells 24 through 31 were treated with WES, and Wells 32 through 45 were treated with NES.

Averaged 30-Day Production Chart-Area 1

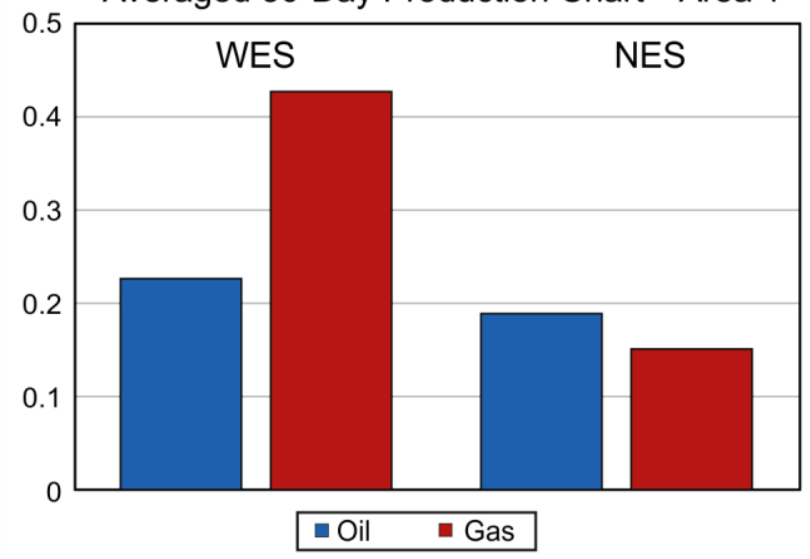

Averaged 30-Day Production Chart-Area 2

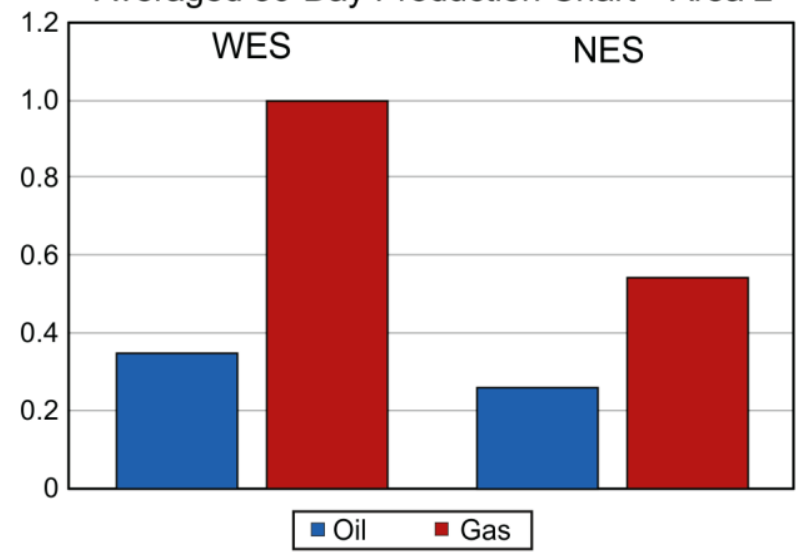

Fig. 17-Averaged 30-day production data of wells treated with WES and NES, indicating that WES yielded more production than NES.

Averaged 90-Day Production Chart-Area 1

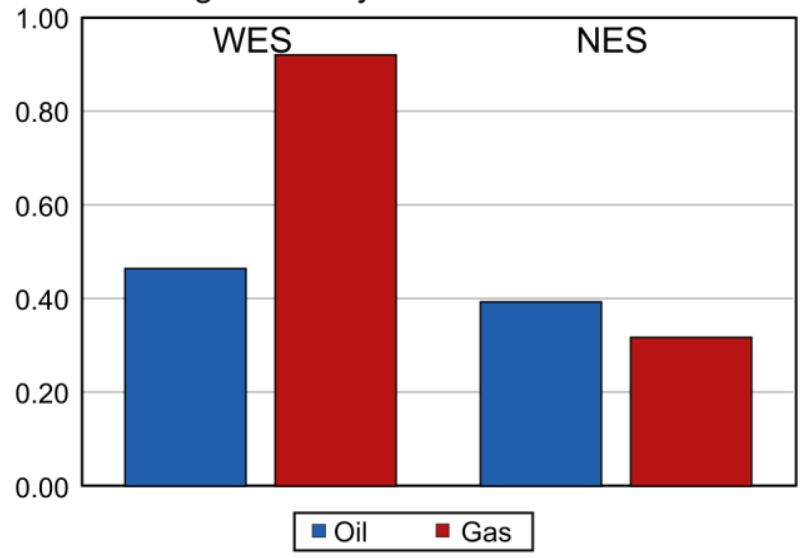

Averaged 90-Day Production Chart-Area 2

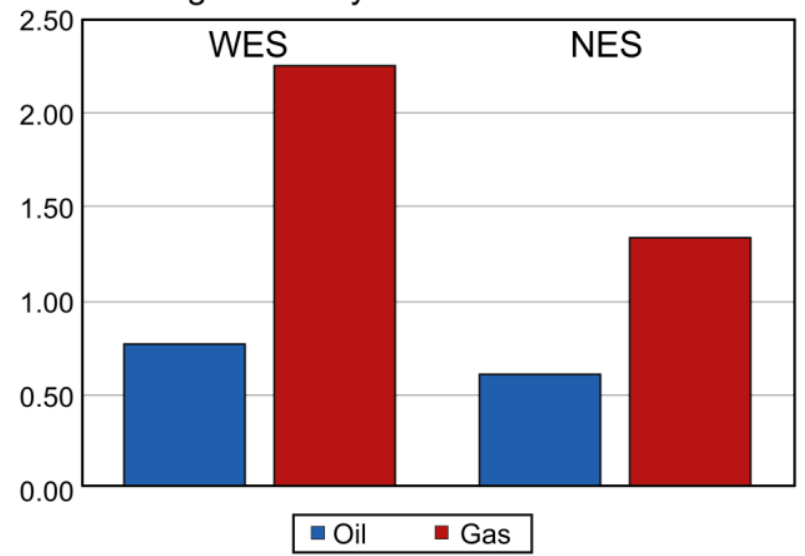

Fig. 18-Averaged 90-day production data of wells treated with WES and NES, indicating that WES yielded more production than NES. 


\title{
Supplementary Information for:
}

Evaluation of Surfactant Performance in Fracturing Fluids for Enhanced Well Productivity in the Unconventional Reservoirs Using Rock-on-a-Chip Approach

\author{
Kai $\mathrm{He}^{1, *}$, Liang $\mathrm{Xu}^{1, *}$, Yuefeng $\mathrm{Gao}^{2}$, Xiaolong $\mathrm{Yin}^{2}$ and Keith Neeves ${ }^{3}$ \\ (1) Multi-Chem, a Halliburton Service, Houston, TX 77032, USA \\ (2) Petroleum Engineering, Colorado School of Mines, Golden, CO 80401, USA \\ (3) Chemical and Biological Engineering, Colorado School of Mines, Golden, CO 80401, USA \\ *: email: Kai.He@ halliburton.com and Liang.Xu@ halliburton.com
}


Detail parameters of $\mathbf{4 5}$ wells analyzed in this study.

Table S1-fracturing parameters for each well and its 30 -day well productivity

\begin{tabular}{|c|c|c|c|c|c|c|c|c|c|}
\hline Well & Stages & Lateral Length $(\mathrm{ft})$ & Stage Spacing (ft) & \begin{tabular}{|l|} 
Cluster \\
\end{tabular} & Cluster Spacing & 30-Day Cum Oil (bbl) & 30-Day Cum Gas (Mscf) & Normalized 30-Day Cum Oil & Normalized 30-Day Cum Gas \\
\hline Well 1 & 8 & 3317 & 402 & 6 & 65 & 1576 & 3343 & 0.06 & 0.13 \\
\hline Well 2 & 11 & 4182 & 387 & 6 & 61 & 7973 & 14451 & 0.17 & 0.31 \\
\hline Well 3 & 12 & 4702 & 398 & 6 & 64 & 17640 & 31136 & 0.31 & 0.55 \\
\hline Well 4 & 9 & 3173 & 380 & 6 & 60 & 16596 & 26958 & 0.58 & 0.94 \\
\hline Well 5 & 17 & 7329 & 390 & 5 & 77 & 20084 & 39457 & 0.16 & 0.32 \\
\hline Well 6 & 17 & 6501 & 400 & 5 & 80 & 17428 & 46256 & 0.16 & 0.42 \\
\hline Well 7 & 17 & 6710 & 410 & 5 & 82 & 15812 & 34582 & 0.14 & 0.30 \\
\hline Well 8 & 11 & 3042 & 280 & 5 & 70 & 10164 & 7562 & 0.30 & 0.23 \\
\hline Well 9 & 15 & 3850 & 250 & 4 & 60 & 14224 & 12172 & 0.25 & 0.21 \\
\hline Well 10 & 16 & 5471 & 353 & 4 & 91 & 16644 & 12936 & 0.19 & 0.15 \\
\hline Well 11 & 16 & 5598 & 350 & 4 & 90 & 15491 & 15804 & 0.17 & 0.18 \\
\hline Well 12 & 15 & 5078 & 350 & 4 & 90 & 13365 & 13461 & 0.18 & 0.18 \\
\hline Well 13 & 17 & 5750 & 344 & 4 & 88 & 20898 & 18050 & 0.21 & 0.18 \\
\hline Well 14 & 20 & 6920 & 350 & 4 & 90 & 18840 & 10767 & 0.14 & 0.08 \\
\hline Well 15 & 18 & 6322 & 356 & 4 & 92 & 20738 & 15810 & 0.18 & 0.14 \\
\hline Well 16 & 18 & 6220 & 350 & 4 & 90 & 26722 & 22504 & 0.24 & 0.20 \\
\hline Well 17 & 18 & 6067 & 341 & 4 & 87 & 16402 & 13269 & 0.15 & 0.12 \\
\hline Well 18 & 18 & 5708 & 320 & 4 & 80 & 12189 & 6943 & 0.12 & 0.07 \\
\hline Well 19 & 13 & 4178 & 335 & 4 & 85 & 8442 & 5024 & 0.16 & 0.09 \\
\hline Well 20 & 16 & 4290 & 270 & 4 & 70 & 13544 & 10773 & 0.20 & 0.16 \\
\hline Well 21 & 14 & 4788 & 356 & 4 & 89 & 14288 & 9294 & 0.21 & 0.14 \\
\hline Well 22 & 14 & 4680 & 340 & 4 & 90 & 11835 & 10099 & 0.18 & 0.15 \\
\hline Well 23 & 15 & 5170 & 350 & 4 & 90 & 10637 & 9278 & 0.14 & 0.12 \\
\hline Well 24 & 16 & 5241 & 336 & 6 & 51 & 21900 & 16423 & 0.26 & 0.20 \\
\hline Well 25 & 16 & 5235 & 332 & 6 & 51 & 23963 & 16302 & 0.29 & 0.19 \\
\hline Well 26 & 11 & 4265 & 420 & 6 & 68 & 22438 & 27200 & 0.48 & 0.58 \\
\hline Well 27 & 11 & 4260 & 415 & 6 & 67 & 26026 & 28268 & 0.56 & 0.60 \\
\hline Well 28 & 11 & 4008 & 392 & 5 & 78 & 11613 & 36677 & 0.26 & 0.83 \\
\hline Well 29 & 11 & 4042 & 396 & 5 & 79 & 12923 & 39746 & 0.29 & 0.89 \\
\hline Well 30 & 10 & 3672 & 398 & 5 & 79 & 10595 & 22147 & 0.29 & 0.60 \\
\hline Well 31 & 8 & 2488 & 324 & 6 & 50 & 6576 & 80530 & 0.33 & 4.05 \\
\hline Well 32 & 15 & 4843 & 327 & 4 & 83 & 17418 & 26265 & 0.24 & 0.36 \\
\hline Well 33 & 15 & 4864 & 330 & 4 & 84 & 20750 & 26878 & 0.28 & 0.37 \\
\hline Well 34 & 16 & 5246 & 333 & 4 & 85 & 14457 & 29171 & 0.17 & 0.35 \\
\hline Well 35 & 11 & 3286 & 300 & 4 & 80 & 13168 & 26215 & 0.36 & 0.73 \\
\hline Well 36 & 11 & 3272 & 300 & 4 & 80 & 13084 & 24487 & 0.36 & 0.68 \\
\hline Well 37 & 20 & 5430 & 270 & 4 & 70 & 17603 & 18770 & 0.16 & 0.17 \\
\hline Well 38 & 14 & 4270 & 310 & 4 & 80 & 16264 & 28369 & 0.27 & 0.47 \\
\hline Well 39 & 17 & 5706 & 340 & 4 & 90 & 20401 & 46071 & 0.21 & 0.47 \\
\hline Well 40 & 18 & 6156 & 350 & 4 & 90 & 21569 & 46245 & 0.19 & 0.42 \\
\hline Well 41 & 15 & 4911 & 335 & 4 & 85 & 8978 & 32898 & 0.12 & 0.45 \\
\hline Well 42 & 17 & 5511 & 325 & 4 & 85 & 13908 & 61966 & 0.15 & 0.66 \\
\hline Well 43 & 17 & 5597 & 342 & 4 & 87 & 26419 & 60992 & 0.28 & 0.64 \\
\hline Well 44 & 17 & 5759 & 333 & 4 & 85 & 26848 & 56709 & 0.27 & 0.58 \\
\hline Well 45 & 14 & 4720 & 346 & 4 & 90 & 31749 & 80569 & 0.48 & 1.22 \\
\hline
\end{tabular}


Table S2- fracturing parameters for each well and its 90-day well productivity

\begin{tabular}{|c|c|c|c|c|c|c|c|c|c|}
\hline Well & Stages & Lateral Length (ft) & Stage Spacing (ft) & Cluster & Cluster Spacing & 90-Day Cum Oil (bbl) & 90-Day Cum Gas (Mscf) & Normalized 90-Day Cum Oil & Normalized 90-Day Cum Gas \\
\hline \begin{tabular}{|l|} 
Well 1 \\
\end{tabular} & 8 & 3317 & 402 & 6 & 65 & 3741 & 9930 & 0.14 & 0.37 \\
\hline \begin{tabular}{l|l} 
Well 2 \\
\end{tabular} & 11 & 4182 & 387 & 6 & 61 & 14212 & 26961 & 0.31 & 0.59 \\
\hline \begin{tabular}{|l|l|} 
Well 3 \\
\end{tabular} & 12 & 4702 & 398 & 6 & 64 & 37380 & 67736 & 0.66 & 1.20 \\
\hline \begin{tabular}{|l|} 
Well 4 \\
\end{tabular} & 9 & 3173 & 380 & 6 & 60 & 33570 & 57299 & 1.18 & 2.01 \\
\hline \begin{tabular}{l|l} 
Well 5 \\
\end{tabular} & 17 & 7329 & 390 & 5 & 77 & 30247 & 56965 & 0.24 & 0.46 \\
\hline \begin{tabular}{l|l} 
Well 6 \\
\end{tabular} & 17 & 6501 & 400 & 5 & 80 & 43913 & 120276 & 0.40 & 1.09 \\
\hline \begin{tabular}{l|l} 
Well 7 \\
\end{tabular} & 17 & 6710 & 410 & 5 & 82 & 37643 & 86889 & 0.33 & 0.76 \\
\hline \begin{tabular}{|l|} 
Well 8 \\
\end{tabular} & 11 & 3042 & 280 & 5 & 70 & 16500 & 11063 & 0.49 & 0.33 \\
\hline \begin{tabular}{|l|} 
Well 9 \\
\end{tabular} & 15 & 3850 & 250 & 4 & 60 & 29766 & 24125 & 0.52 & 0.42 \\
\hline Well 10 & 16 & 5471 & 353 & 4 & 91 & 44083 & 33173 & 0.50 & 0.38 \\
\hline Well 11 & 16 & 5598 & 350 & 4 & 90 & 33530 & 29505 & 0.37 & 0.33 \\
\hline Well 12 & 15 & 5078 & 350 & 4 & 90 & 30058 & 32482 & 0.39 & 0.43 \\
\hline Well 13 & 17 & 5750 & 344 & 4 & 88 & 41483 & 38556 & 0.42 & 0.39 \\
\hline Well 14 & 20 & 6920 & 350 & 4 & 90 & 35532 & 21896 & 0.26 & 0.16 \\
\hline Well 15 & 18 & 6322 & 356 & 4 & 92 & 44900 & 36533 & 0.39 & 0.32 \\
\hline Well 16 & 18 & 6220 & 350 & 4 & 90 & 54169 & 50610 & 0.48 & 0.45 \\
\hline Well 17 & 18 & 6067 & 341 & 4 & 87 & 31425 & 26713 & 0.29 & 0.24 \\
\hline Well 18 & 18 & 5708 & 320 & 4 & 80 & 26734 & 19113 & 0.26 & 0.19 \\
\hline Well 19 & 13 & 4178 & 335 & 4 & 85 & 18460 & 12925 & 0.34 & 0.24 \\
\hline Well 20 & 16 & 4290 & 270 & 4 & 70 & 31305 & 27931 & 0.46 & 0.41 \\
\hline \begin{tabular}{|l|} 
Well 21 \\
\end{tabular} & 14 & 4788 & 356 & 4 & 89 & 30822 & 20299 & 0.46 & 0.30 \\
\hline \begin{tabular}{|l|} 
Well 22 \\
\end{tabular} & 14 & 4680 & 340 & 4 & 90 & 24142 & 20223 & 0.37 & 0.31 \\
\hline Well 23 & 15 & 5170 & 350 & 4 & 90 & 20650 & 14437 & 0.27 & 0.19 \\
\hline Well 24 & 16 & 5241 & 336 & 6 & 51 & 51066 & 42857 & 0.61 & 0.51 \\
\hline Well 25 & 16 & 5235 & 332 & 6 & 51 & 62462 & 48057 & 0.75 & 0.57 \\
\hline Well 26 & 11 & 4265 & 420 & 6 & 68 & 44893 & 60179 & 0.96 & 1.28 \\
\hline Well 27 & 11 & 4260 & 415 & 6 & 67 & 52236 & 56563 & 1.11 & 1.21 \\
\hline Well 28 & 11 & 4008 & 392 & 5 & 78 & 29063 & 96077 & 0.66 & 2.18 \\
\hline \begin{tabular}{|l|} 
Well 29 \\
\end{tabular} & 11 & 4042 & 396 & 5 & 79 & 32017 & 101962 & 0.72 & 2.29 \\
\hline Well 30 & 10 & 3672 & 398 & 5 & 79 & 24176 & 52204 & 0.66 & 1.42 \\
\hline Well 31 & 8 & 2488 & 324 & 6 & 50 & 13081 & 171603 & 0.66 & 8.62 \\
\hline Well 32 & 15 & 4843 & 327 & 4 & 83 & 44058 & 67178 & 0.61 & 0.92 \\
\hline \begin{tabular}{|l|} 
Well 33 \\
\end{tabular} & 15 & 4864 & 330 & 4 & 84 & 45193 & 65454 & 0.62 & 0.90 \\
\hline Well 34 & 16 & 5246 & 333 & 4 & 85 & 41139 & 73645 & 0.49 & 0.88 \\
\hline Well 35 & 11 & 3286 & 300 & 4 & 80 & 25519 & 45409 & 0.71 & 1.26 \\
\hline Well 36 & 11 & 3272 & 300 & 4 & 80 & 23941 & 37894 & 0.67 & 1.05 \\
\hline Well 37 & 20 & 5430 & 270 & 4 & 70 & 41147 & 40433 & 0.38 & 0.37 \\
\hline Well 38 & 14 & 4270 & 310 & 4 & 80 & 35854 & 66836 & 0.60 & 1.12 \\
\hline \begin{tabular}{|l|} 
Well 39 \\
\end{tabular} & 17 & 5706 & 340 & 4 & 90 & 59995 & 141262 & 0.62 & 1.46 \\
\hline Well 40 & 18 & 6156 & 350 & 4 & 90 & 56416 & 122296 & 0.51 & 1.10 \\
\hline Well 41 & 15 & 4911 & 335 & 4 & 85 & 24080 & 101514 & 0.33 & 1.38 \\
\hline Well 42 & 17 & 5511 & 325 & 4 & 85 & 44011 & 167447 & 0.47 & 1.79 \\
\hline \begin{tabular}{|l|} 
Well 43 \\
\end{tabular} & 17 & 5597 & 342 & 4 & 87 & 73920 & 178855 & 0.78 & 1.88 \\
\hline Well 44 & 17 & 5759 & 333 & 4 & 85 & 66146 & 164746 & 0.68 & 1.68 \\
\hline $\begin{array}{ll}\text { Well } 45 \\
\end{array}$ & 14 & 4720 & 346 & 4 & 90 & 68423 & 198162 & 1.04 & 3.00 \\
\hline
\end{tabular}

Oil Production Difference between WES and NES. WES yielded more oils than NES. An average of the oil production differences per well for both areas in 30 and 90 days were reported below in Table S3.

\begin{tabular}{|c|c|c|}
\hline \multicolumn{3}{|c|}{ TABLE S3-OIL PRODUCTION DIFFERENCE BETWEEN WES AND NES } \\
\hline Oil Production difference (bbl per well) & 30 day & 90 day \\
\hline Area 1 & 2734 & 5246 \\
\hline Area 2 & 6433 & 11467 \\
\hline
\end{tabular}

